\title{
Association of locomotor complaints and disability in the Rotterdam study
}

Else Odding, Hans A Valkenburg, Douwe Algra, Frank A Vandenouweland, Diederick E Grobbee, Albert Hofman

\begin{abstract}
Objective-To determine the association between joint complaints and locomotor disability.

Methods-During a home interview survey 1901 men and 3135 women aged 55 years and over (the Rotterdam Study) were asked about joint pain and morning stiffiness in the past month, and locomotor disability was assessed by six questions from the Health Assessment Questionnaire (HAQ).

Results-The prevalence of locomotor disability was $24 \cdot 5 \%$ for men and $40 \cdot 5 \%$ for women. The prevalence of joint pain in men was $0.7 \%$ for pain in the hips, knees, and feet simultaneously, $3 \cdot 7 \%$ for pain at two joint sites, $\mathbf{1 6 . 0} \%$ for pain at one joint site, and $20.4 \%$ for pain in the hips and/or knees and/or feet (any joint site); the corresponding estimates for women were $1.9 \%, 9.0 \%, 23.7 \%$, and $34.5 \%$, respectively. The prevalence of generalised morning stiffiness was $4.9 \%$ for men and $10 \cdot 4 \%$ for women. The age adjusted odds ratios for locomotor disability in men ranged from 2.4 of pain at one joint site to $8 \cdot 8$ of pain at all three joint sites; for women these odds ratios varied between $2 \cdot 5$ and $5 \cdot 7$, respectively. The age adjusted odds ratios of generalised morning stiffness were $8 \cdot 0$ for men and $7 \cdot 3$ for women. Conclusion-There is a strong and independent association between locomotor disability and age, joint pain, and generalised morning stiffiness in people aged 55 years and over. The odds for locomotor disability increase onefold for every year increase in age, while the presence of generalised morning stiffiness is of greater influence than the presence of joint pain.
\end{abstract}

(Ann Rheum Dis 1995; 54: 721-725)

Disability in the activities of daily living is a major problem in people aged 55 years and over. Disability, as evaluated by the Stanford Health Assessment Questionnaire in an unselected population of $\mathbf{5 5}$ years and older in a district of Rotterdam, the Netherlands (the Rotterdam Study), ${ }^{12}$ was present in $22 \%$ of the men and $36 \%$ of the women. The prevalence of locomotor disability, defined as disability in activities related to lower limb function, was of the same magnitude. Locomotor disability was associated with female gender, increasing age, living in a home for the elderly, low education, and low income. ${ }^{1}$ It is conceivable that joint complaints of the lower limbs are associated with locomotor disability. Data from the National Health and Nutrition Examination Survery and the Framingham Study suggested a large impact of arthritis on disability in the activities of daily living related to lower limb function..$^{3-8}$ The major disadvantage of these studies is the use of the term arthritis, which is an ill defined entity. Even when arthritis is clearly defined, it is not this diagnosis which troubles the patients; they suffer from its consequences-pain, stiffness, restricted range of motion of the joint, etc. A recent study in the United Kingdom reported on the importance of knee pain for disability. ${ }^{9}$ In addition, there is an important proportion of the population who do not seek medical care for their complaint. The present study, as part of the Rotterdam Study of a cohort of 5036 people, analysed the association of locomotor disability with self reported pain in the joints of the lower limb and generalised morning stiffness.

\section{Population and methods}

POPULATION

The Rotterdam Study is a prospective follow up study of the incidence and risk factors of chronic disease and disability in persons aged 55 years and over in the general population. The source population comprises all residents aged 55 years and over on 1 January 1989 living in the Ommoord district of Rotterdam, including the residents of the six homes for the eldery in the district. ${ }^{2}$ Baseline data on all 10810 eligible people were gathered from April 1990 to July 1993.

The present study concerns those participants who took part in the study between April 1990 and July 1992. At this stage of the study, 2398 men and 4081 women were invited to participate: 1937 men $(80.8 \%)$ and 3255 women $(79.8 \%)$ did so, but because of incomplete interview data, 36 men and 120 women were subsequently excluded from the analysis. Complete data were therefore available for 1901 men (79.3\%) and 3135 women $(76 \cdot 8 \%)$.

\section{METHODS}

The analysis focused on the association of lower limb joint pain and generalised morning stiffness with locomotor disability. Locomotor disability was defined as proposed by the International Classification of Impairments, 
Disabilities and Handicaps and comprises the relevant items from the ambulation subcategory: walking, climbing stairs, getting in and out of bed and a car, bending, and rising from a chair. ${ }^{10}$ The Stanford Health Assessment Questionnaire (HAQ) was used to assess disability. ${ }^{11-14}$ The HAQ formed part of an one hour home interview carried out by one of nine intensively trained interview assistants. It measures disability in eight categories (dressing and grooming, rising, reach, hygiene, eating, walking, grip, and activity), each of which consists of two to four questions starting with: 'Are you able to...'. Each question is answered by one of four possible answers, with scores: $0=$ without difficulty; $1=$ with difficulty; $2=$ with much difficulty; $3=$ unable to do. Special attention was paid to standardisation of the scoring system of the HAQ. The interviewers were instructed to score the answers given by the participant, not their own assessment of the participant's ability to carry out the various tasks. The highest score on any question within a category constituted the score for that component. A Locomotor Disability Index (LDI) was defined as the mean of the scores on the six questions most related to lower limb function. These were: getting in and out of bed, rising from an armless straight chair, bending down to pick up clothing from the floor, getting in and out of a car, walking outdoors on flat ground and climbing stairs. The cut off for moderate disability was 1 for the separate functions and 0.5 for the LDI; that for severe disability was 2 for the separate functions and 1.0 for the LDI.

Locomotor factors assessed at the interview which could possibly be associated with locomotor disability were joint pain and generalised morning stiffness. Pain was assessed by asking the participants if they suffered from pain or other complaints in their joints during the past month and, if so, which joints troubled them most. A manikin was used to check all joint sites. For the current analyses, we used the data on pain in the joints of the lower limbs, irrespective of the fact that other joints might be more troublesome to the participant. Pain at a joint site was defined as pain in the left or right joint, or both. Several degrees of joint pain were distinguished: pain in the hips and/or knees and/or feet (any joint site), pain at all three joint sites simultaneously, pain at two joint sites (hips and knees, hips and feet, or knees and feet), and finally pain at one joint site (pain in the hips only, knees only, or feet only). Duration of generalised morning stiffness was assessed at three levels (less than 30 minutes, 30-60 minutes, more than 60 minutes), and subsequently dichotomised to no stiffness or stiffness lasting 30 minutes or more.

DATA ANALYSIS

Data were analysed for men and women separately. Because the inhabitants of the homes for the eldery are considered to be independent in the activities of daily living as assessed by means of the LDI, we included them in the current analyses.

As the rates for severe disability were low, the analyses of association with locomotor disability were restricted to moderate disability. Crude and adjusted prevalence odds ratios for locomotor disability were estimated using a multiple logistic regression model. The odds ratios of joint pain were adjusted for age and generalised morning stiffness, while the odds ratios of generalised morning stiffness were adjusted for age and the four categories of joint pain. Age, joint pain, generalised morning stiffness and selected demographic variables were entered together in a mutiple logistic regression model of locomotor disability to estimate adjusted odds ratios and aetiological fractions for all independent variables. The aetiological fraction (EF) is defined as the proportion of disabled persons to whom the determinant of interest is applicable. ${ }^{15}$ It was calculated using the formula:

$$
\mathrm{EF}=\mathrm{p}(\mathrm{aOR}-1) /\{\mathrm{p}(\mathrm{aOR}-1)+1\}
$$

where $p$ is the prevalence of the determinant in the population and $\mathrm{aOR}$ is the odds ratio adjusted for age, joint complaints, and demographic variables. In this analysis, locomotor disability was dichotomised at the cut off point of 0.50 ; joint pain and generalised morning stiffness were dichotomous variables. The reference categories were: for living accommodation, living independently; for marital status, being married; for living situation, not living alone; for education, primary education; and for income, below median income.

\section{Results}

Table 1 presents some selected baseline characteristics of the study population. In table 2 the prevalence of disability in the six activities most related to lower limb function, and the LDI, are given by gender and age. The prevalence of moderate disability in the separate functions, and the LDI, were 1.5 to 1.8 times greater in women than in men, and the figures for severe disability were 1.7 to 2.2 times greater in women than in men. In each gender the prevalences of disability in the separate functions were about the same. Table 3 summarises the prevalences of pain in the joints of the lower limbs and generalised morning stiffness. Pain in at least one joint of the lower limbs (any joint site) was present in $20 \%$ of the men and in $35 \%$ of the women. Of the men, $16.0 \%$ had pain at one joint site only (most often the knee $(8 \cdot 6 \%)$ ), $3.7 \%$ at two joint sites (most often the hip and knee $(2 \cdot 2 \%))$, and $0 \cdot 7 \%$ had pain at all

Table 1 Selected baseline characteristics of the participants in the Rotterdam Study

\begin{tabular}{lcc}
\hline & Men & Women \\
\hline Number & $1901(37 \cdot 7 \%)$ & $3135(62 \cdot 23 \%)$ \\
Age (yr) & $55 \cdot 0-94 \cdot 6$ & $55 \cdot 0-99 \cdot 2$ \\
$\quad$ Range & $69 \cdot 5(0 \cdot 2)$ & $71 \cdot 4(0 \cdot 2)$ \\
$\quad$ Mean (SD) & & \\
Living accommodation & $1819(95 \cdot 7 \%)$ & $2819(89 \cdot 9 \%)$ \\
$\quad$ Independent & $82(4 \cdot 3 \%)$ & $316(10 \cdot 1 \%)$ \\
Homes for the elderly & &
\end{tabular}


Table 2 Prevalence of moderate and severe disability in separate lower limb functions by single questions and locomotor disability index (LDI) in men and women by age

\begin{tabular}{|c|c|c|c|c|c|c|c|c|c|c|}
\hline & \multicolumn{8}{|c|}{ Age (yr) } & & \\
\hline & \multicolumn{2}{|c|}{$55-64$} & \multicolumn{2}{|c|}{$65-74$} & \multicolumn{2}{|c|}{$75-84$} & \multicolumn{2}{|l|}{$85+$} & \multicolumn{2}{|l|}{ Total group } \\
\hline & $M$ & $S$ & $M$ & $S$ & $M$ & $S$ & $M$ & $S$ & $M$ & $S$ \\
\hline $\begin{array}{l}\text { Men } \\
\text { Getting in/out bed } \\
\text { Rising from chair } \\
\text { Bending } \\
\text { Getting in/out of car } \\
\text { Walking } \\
\text { Climbing stairs } \\
\text { LDI }\end{array}$ & $\begin{array}{r}(\mathbf{n} \\
9 \cdot 8 \\
9 \cdot 3 \\
12 \cdot 6 \\
8 \cdot 8 \\
9 \cdot 0 \\
11 \cdot 2 \\
10 \cdot 1\end{array}$ & $\begin{array}{l}635) \\
1 \cdot 3 \\
1 \cdot 6 \\
4 \cdot 7 \\
2 \cdot 2 \\
2 \cdot 2 \\
2 \cdot 5 \\
3 \cdot 9\end{array}$ & $\begin{array}{r}(\mathrm{n} \\
18 \cdot 6 \\
17 \cdot 9 \\
16 \cdot 4 \\
17 \cdot 3 \\
21 \cdot 4 \\
24 \cdot 5 \\
21 \cdot 7\end{array}$ & $\begin{array}{r}762) \\
2 \cdot 5 \\
3 \cdot 5 \\
6 \cdot 4 \\
4 \cdot 7 \\
6 \cdot 4 \\
7 \cdot 0 \\
7 \cdot 5\end{array}$ & $\begin{array}{r}(\mathrm{n}= \\
30 \cdot 8 \\
34 \cdot 7 \\
28 \cdot 6 \\
38 \cdot 4 \\
40 \cdot 7 \\
44 \cdot 1 \\
41 \cdot 8\end{array}$ & $\begin{array}{r}426) \\
5 \cdot 9 \\
9 \cdot 9 \\
12 \cdot 7 \\
14 \cdot 8 \\
17 \cdot 5 \\
19 \cdot 2 \\
23 \cdot 0\end{array}$ & $\begin{array}{r}(\mathrm{n} \\
55 \cdot 1 \\
60 \cdot 3 \\
56 \cdot 6 \\
72 \cdot 7 \\
67 \cdot 1 \\
79 \cdot 2 \\
74 \cdot 4\end{array}$ & $\begin{array}{l}78) \\
19 \cdot 2 \\
29 \cdot 5 \\
36 \cdot 8 \\
46 \cdot 8 \\
44 \cdot 7 \\
50 \cdot 6 \\
55 \cdot 1\end{array}$ & $\begin{array}{l}(\mathrm{n}= \\
19.9(18 \cdot 1 \text { to } 21 \cdot 7) \\
20.5(18 \cdot 7 \text { to } 22 \cdot 3) \\
19.5(17 \cdot 7 \text { to } 21 \cdot 3) \\
21.4(19 \cdot 6 \text { to } 23 \cdot 2) \\
23.4(21.5 \text { to } 25 \cdot 3) \\
26.7(24.7 \text { to } 28 \cdot 7) \\
24.5(22.6 \text { to } 26 \cdot 4)\end{array}$ & $\begin{array}{l}901) \\
3.5(2.7 \text { to } 4.3) \\
5.4(4.4 \text { to } 6.4) \\
8.5(7 \cdot 2 \text { to } 9 \cdot 8) \\
7.8(6.6 \text { to } 9.0) \\
9.0(7.7 \text { to } 10.3) \\
10.0(8.7 \text { to } 11.3) \\
11.7(10.3 \text { to } 13.1)\end{array}$ \\
\hline $\begin{array}{l}\text { Women } \\
\text { Getting in/out bed } \\
\text { Rising from chair } \\
\text { Bending } \\
\text { Getting in/out of car } \\
\text { Walking } \\
\text { Climbing stairs } \\
\text { LDI }\end{array}$ & $\begin{array}{l}\text { (n } \\
17 \cdot 1 \\
14 \cdot 7 \\
17 \cdot 8 \\
17 \cdot 1 \\
15 \cdot 7 \\
24 \cdot 3 \\
17 \cdot 6\end{array}$ & $\begin{array}{r}950) \\
1 \cdot 8 \\
2 \cdot 2 \\
6 \cdot 0 \\
4 \cdot 1 \\
3 \cdot 5 \\
5 \cdot 1 \\
6 \cdot 8\end{array}$ & $\begin{array}{l}\text { (n } \\
27 \cdot 5 \\
26 \cdot 5 \\
27 \cdot 5 \\
32 \cdot 0 \\
28 \cdot 0 \\
43 \cdot 0 \\
33 \cdot 8\end{array}$ & $\begin{array}{r}1090) \\
3 \cdot 8 \\
6 \cdot 3 \\
9 \cdot 6 \\
10 \cdot 1 \\
9 \cdot 0 \\
11 \cdot 6 \\
15 \cdot 8\end{array}$ & $\begin{array}{r}(n= \\
42 \cdot 4 \\
48 \cdot 0 \\
44 \cdot 8 \\
57 \cdot 0 \\
51 \cdot 6 \\
64 \cdot 5 \\
57 \cdot 8\end{array}$ & \begin{tabular}{r|}
$773)$ \\
$8 \cdot 7$ \\
$16 \cdot 2$ \\
$19 \cdot 8$ \\
$25 \cdot 8$ \\
$22 \cdot 8$ \\
$30 \cdot 0$ \\
$36 \cdot 0$
\end{tabular} & $\begin{array}{r}(\mathrm{n} \\
68 \cdot 0 \\
80 \cdot 1 \\
71 \cdot 7 \\
88 \cdot 2 \\
85 \cdot 2 \\
88 \cdot 0 \\
89 \cdot 1\end{array}$ & $\begin{array}{l}322) \\
24 \cdot 2 \\
44 \cdot 7 \\
40 \cdot 8 \\
59 \cdot 6 \\
59 \cdot 9 \\
65 \cdot 0 \\
73 \cdot 9\end{array}$ & $\begin{array}{l}(\mathrm{n}= \\
32.2(30.6 \text { to } 33 \cdot 8) \\
33.7(32.0 \text { to } 35.4) \\
33.3(31.7 \text { to } 34.9) \\
39.3(37.6 \text { to } 41.0) \\
35.9(34.2 \text { to } 37.6) \\
47.2(45.5 \text { to } 48.9) \\
40.5(38.8 \text { to } 42.2)\end{array}$ & $\begin{array}{l}135) \\
6.5(5.6 \text { to } 7 \cdot 4) \\
11.4(10.3 \text { to } 12.5) \\
14.2(13.0 \text { to } 15.4) \\
17.1(15.8 \text { to } 18.4) \\
15.9(14.6 \text { to } 17 \cdot 2) \\
19.6(18.2 \text { to } 21 \cdot 0) \\
24.0(22.5 \text { to } 25.5)\end{array}$ \\
\hline
\end{tabular}

Values are percentages, with $95 \%$ confidence intervals for Total group.

$M=$ Moderate disability; question score $\geq 1$, index $\geq 0.50 ; S=$ severe disability: question score $\geq 2$, index $\geq 1.00$.

three joint sites. Among women, 23.7\% suffered from pain at one joint site (most often the knee $(12 \cdot 8 \%)), 9 \cdot 0 \%$ at two joint sites (most often the hip and knee $(5 \cdot 1 \%))$, and $1.9 \%$ had pain at all three joint sites. Tests for linear trend showed no significant increase with age of the prevalence of pain in any pain category for women; for men there was a borderline significant increase with age of the prevalence for joint pain anywhere $(p=0.062)$, and a significant increase with age for men with pain at one joint site $(p=0.020)$. Generalised morning stiffness occurred in nearly $5 \%$ of the men and more than $10 \%$ of the women. In women, this stiffness increased significantly with age $(p=0.0001)$, from $8.7 \%$ in the age group 55-64 years to $16 \cdot 8 \%$ in women of 85 years and older. In men it increased slightly with age up to 84 years and decreased thereafter (not significant)

The prevalence of locomotor disability increased linearly with the number of joint sites that were painful (table 4). The values for locomotor disability were greater in those suffering from generalised morning stiffness. Although the prevalences of stiffness in all men and women were of the same order as those for pain at two joint sites, there was more disability in relation with generalised morning stiffness

Table 3 Prevalence of locomotor complaints in men and women by age

\begin{tabular}{|c|c|c|c|c|c|}
\hline & \multicolumn{4}{|c|}{ Age (yr) } & \multirow[t]{2}{*}{ Total group } \\
\hline & $55-64$ & $65-74$ & $75-84$ & $85+$ & \\
\hline \multicolumn{6}{|l|}{ Men } \\
\hline $\begin{array}{l}\text { Number } \\
\text { Joint pain }\end{array}$ & 635 & 762 & 426 & 78 & 1901 \\
\hline Any joint site & $18 \cdot 7$ & $20 \cdot 1$ & $22 \cdot 5$ & $25 \cdot 6$ & $20.4(18.6$ to 22.2$)$ \\
\hline One joint site & $14 \cdot 2$ & $15 \cdot 6$ & $18 \cdot 1$ & $23 \cdot 1$ & $16.0(14.4$ to 17.6$)$ \\
\hline Two joint sites & $3 \cdot 8$ & 3.8 & $4 \cdot 0$ & $1 \cdot 3$ & $3.7(2.9$ to 4.5$)$ \\
\hline Three joint sites & $0 \cdot 8$ & $0 \cdot 7$ & 0.5 & $1 \cdot 3$ & $0.7(0.3$ to 1.1$)$ \\
\hline Morning stiffness & $4 \cdot 1$ & $4 \cdot 9$ & $6 \cdot 1$ & $5 \cdot 1$ & $4.9(3.9$ to 5.9$)$ \\
\hline \multicolumn{6}{|l|}{ Women } \\
\hline Number & 950 & 1090 & 773 & 322 & 3135 \\
\hline Joint pain & & & & & \\
\hline Any joint site & $32 \cdot 5$ & $37 \cdot 1$ & $33 \cdot 9$ & $33 \cdot 5$ & $34 \cdot 5(32 \cdot 8$ to $36 \cdot 2)$ \\
\hline One joint site & $22 \cdot 4$ & $25 \cdot 2$ & $23 \cdot 4$ & $22 \cdot 7$ & $23.7(22.2$ to $25 \cdot 2)$ \\
\hline Two joint sites & $8 \cdot 2$ & $9 \cdot 4$ & $9 \cdot 1$ & $9 \cdot 3$ & $9.0(8.0$ to 10.0$)$ \\
\hline Three joint sites & 1.9 & $2 \cdot 4$ & $1 \cdot 4$ & $1 \cdot 6$ & $1.9(1.4$ to 2.4$)$ \\
\hline Morning stiffness & $8 \cdot 7$ & $9 \cdot 2$ & $11 \cdot 6$ & $16 \cdot 8$ & $10.4(9.3$ to 11.5$)$ \\
\hline
\end{tabular}

Values are percentages, with $95 \%$ confidence intervals for Total group.

Any joint site = Pain in hips and/or knees and/or feet; one joint site $=$ pain in hips or knees or feet; two joint sites = pain in hips and knees, or hips and feet, or knees and feet; three joint sites = pain in hips and knees and feet. than with joint pain. Table 5 shows the association between locomotor disability and joint pain measured by the odds ratio. The odds ratios for disability increased with the number of joints affected in both sexes, and were somewhat greater for men than for women, even though both locomotor disability and joint pain occurred significantly more often in women than in men. After adjustment for age, the odds ratios increased substantially in virtually all strata of joint pain. Analysis of the odds ratios for locomotor disability in 10 year age groups yielded the greatest odds ratios in the youngest participants (55-64 years), and these decreased in the older age strata. Logistic regression which included the interaction term of age and pain resulted in an excessive increase in the odds ratios (data not shown). When generalised morning stiffness was entered in the logistic regression, the odds ratios of joint pain in women decreased slightly. The odds ratios adjusted for age and generalised morning stiffness were of the same magnitude or higher than the crude odds ratios.

The age adjusted odds ratios for locomotor disability of morning stiffness were 8.0 (95\% confidence interval 4.9 to 13.0 ) for men and $7 \cdot 3(5 \cdot 4$ to $7 \cdot 7)$ for women. Adjustment of these odds ratios for the four categories of joint pain did not significantly change these estimates.

Table 4 Prevalence of locomotor disability in men and women according to joint complaints

\begin{tabular}{lrrrrr}
\hline & \multicolumn{2}{c}{ Men } & & \multicolumn{2}{c}{ Women } \\
\cline { 2 - 3 } \cline { 6 - 6 } \cline { 5 - 6 } & No & $\%$ & & No & $\%$ \\
\hline Joint pain & & & & \\
Nowhere & 1513 & $19 \cdot 8$ & & 2052 & $31 \cdot 2$ \\
Any joint site & 388 & $42 \cdot 8$ & & 1083 & $58 \cdot 1$ \\
One joint site & 304 & $39 \cdot 5$ & & 742 & $53 \cdot 2$ \\
Two joint sites & 71 & $53 \cdot 5$ & & 281 & $68 \cdot 0$ \\
$\quad$ Three joint sites & 13 & $61 \cdot 5$ & & 60 & $71 \cdot 7$ \\
Morning stiffness & & & & & \\
No & 1808 & $22 \cdot 4$ & & 2808 & $36 \cdot 2$ \\
Yes & 93 & $64 \cdot 5$ & & 327 & $77 \cdot 1$ \\
\hline
\end{tabular}

Values are percentages.

Note that the sum of the numbers in the various strata of joint pain is greater than the total number of men and women present in the study: the stratum 'any joint site' comprises people who are also present in one of the other categories of pain. 
Table 5 Odds ratios (95\% confidence intervals) for locomotor disability of joint pain adjusted for age and morning stiffness

\begin{tabular}{|c|c|c|c|}
\hline & \multicolumn{3}{|l|}{ Odds ratio } \\
\hline & Crude & Adjusted for age & $\begin{array}{l}\text { Adjusted for age } \\
\text { and morning stiffness }\end{array}$ \\
\hline \multicolumn{4}{|l|}{ Men } \\
\hline Any joint site & $3.0(2.4$ to 3.9$)$ & $3.4(2.6$ to 4.4$)$ & $3.1(2.3$ to 4.0$)$ \\
\hline One joint site & $2.4(1.8$ to 3.0$)$ & $2.4(1.8$ to 3.2$)$ & $2.3(1.7$ to 3.0$)$ \\
\hline Two joint sites & $3.8(2.3$ to 6.1$)$ & $4.9(2.9$ to 8.3$)$ & $4.3(2.5$ to 7.4$)$ \\
\hline Three joint sites & $5.0(1.6$ to 15.4$)$ & $8.8(2.6$ to 29.3$)$ & $6.7(1.8$ to $24 \cdot 4)$ \\
\hline \multicolumn{4}{|l|}{ Women } \\
\hline Any joint site & $3.0(2.6$ to 3.6$)$ & $4.5(3.8$ to 5.4$)$ & $4.0(3.4$ to 4.9$)$ \\
\hline One joint site & $2.0(1.7$ to 2.3$)$ & $2.5(2.0$ to 3.0$)$ & $2.4(2.0$ to 3.0$)$ \\
\hline Two joint sites & $3.5(2.7$ to 4.5$)$ & $4.7(3.5$ to 6.3$)$ & $4.0(3.0$ to 5.4$)$ \\
\hline Three joint sites & $3.8(2 \cdot 2$ to $6 \cdot 7)$ & $5 \cdot 7(3.1$ to $10 \cdot 4)$ & $5.2(2.8$ to 9.9$)$ \\
\hline
\end{tabular}

Analysis of the six separate functions which constitute the LDI showed that the odds ratios of joint pain and generalised morning stiffness for disability in these functions were of the same magnitude as those presented in table 5 and the previous paragraph (data not shown).

Table 6 shows the results of a multiple logistic regression model. Significantly increased odds for locomotor disability were observed in both men and women suffering from joint pain and generalised morning stiffness and living in a home for the elderly. In women there were almost significantly increased odds ratios for locomotor disability of being widowed or divorced. Men with a net annual income above the median were significantly less often disabled, while in women this determinant just failed to reach significance. The last column for each gender shows the proportion of disability in the total population that was attributable to the determinants of interest. For example, among men aged 55 years and over, it can be estimated that about $27 \%$ of all locomotor disability in the general population is attributable to pain in the joints of the lower limbs. Generalised morning stiffness and living in a home for the elderly are the two other determinants which contribute to the occurrence of locomotor disability. The various demographic variables contribute very little or not at all to the occurrence of locomotor disability in the population at large.

\section{Discussion}

In a general population of Dutch people aged 55 years and over, $20-27 \%$ of the men and $32-47 \%$ of the women reported disability in six lower limb functions. Twenty percent of the men suffered from pain in at least one of the

Table 6 Adjusted odds ratios and aetiological fractions for locomotor disability adjusted for age, joint complaints, and demographic variables

\begin{tabular}{|c|c|c|c|c|c|c|}
\hline & \multicolumn{3}{|l|}{ Men } & \multicolumn{3}{|c|}{ Women } \\
\hline & $a O R$ & $95 \% C I$ & $E F$ & $a O R$ & $95 \% C I$ & $E F$ \\
\hline $\begin{array}{l}\text { Pain any joint site } \\
\text { Morning stiffness } \\
\text { Home for the elderly } \\
\text { Widowed } \\
\text { Divorced } \\
\text { Unmarried } \\
\text { Living alone } \\
\text { Secondary education } \\
\text { High education } \\
\text { Above median income }\end{array}$ & $\begin{array}{l}2 \cdot 8 \\
4 \cdot 9 \\
5 \cdot 8 \\
0 \cdot 7 \\
0 \cdot 6 \\
0 \cdot 8 \\
1 \cdot 3 \\
0 \cdot 8 \\
0 \cdot 8 \\
0 \cdot 6\end{array}$ & $\begin{array}{l}(2.0 \text { to } 3.8) \\
(2.7 \text { to } 9.0) \\
(2.5 \text { to } 13.6) \\
(0.4 \text { to } 1.2) \\
(0.3 \text { to } 1.4) \\
(0.4 \text { to } 1.9) \\
(0.8 \text { to } 2 \cdot 3) \\
(0.6 \text { to } 1.1) \\
(0.5 \text { to } 1.4) \\
(0.4 \text { to } 0.8)\end{array}$ & $\begin{array}{l}26 \cdot 8 \\
14 \cdot 8 \\
14 \cdot 2 \\
- \\
- \\
- \\
(4 \cdot 7) \dagger \\
- \\
-\end{array}$ & $\begin{array}{l}4 \cdot 2 \\
6 \cdot 6 \\
5 \cdot 2 \\
1 \cdot 3 \\
1 \cdot 5 \\
1 \cdot 1 \\
0 \cdot 8 \\
0 \cdot 9 \\
0 \cdot 8 \\
0 \cdot 9\end{array}$ & $\begin{array}{l}(3.4 \text { to } 5 \cdot 2) \\
(4.6 \text { to } 9 \cdot 6) \\
(3.0 \text { to } 9 \cdot 0) \\
(0.9 \text { to } 1.8) \\
(0.9 \text { to } 2 \cdot 4) \\
(0.7 \text { to } 1.7) \\
(0.6 \text { to } 1 \cdot 1) \\
(0.8 \text { to } 1 \cdot 2) \\
(0.5 \text { to } 1.3) \\
(0.7 \text { to } 1 \cdot 2)\end{array}$ & $\begin{array}{l}53 \cdot 2 \\
35 \cdot 8 \\
24 \cdot 9 \\
(10 \cdot 5) \dagger \\
(3 \cdot 7) \dagger \\
(1 \cdot 0) \dagger \\
= \\
= \\
-\end{array}$ \\
\hline
\end{tabular}

aOR = Odds ratio adjusted for all variables in the models; $-=a \mathrm{aOR}<1$; taOR not significantly greater than $1.95 \% \mathrm{CI}=95 \%$ confidence interval of $\mathrm{aOR} ; \mathrm{EF}=$ aetiological fraction $=p(a \mathrm{OR}-$ 1) $/\{$ p(aOR-1) +1$\}$ joints of the lower limbs, while fewer than $1 \%$ of the men had pain in the hips, knees, and feet simultaneously. Thirty five percent of the women reported joint pain somewhere, and almost $2 \%$ had pain at three joint sites simultaneously. Generalised morning stiffness occurred in almost $5 \%$ of the males and more than $10 \%$ of the females. Age, joint pain, and morning stiffness were strongly and independently associated with disability.

Apart from age and joint complaints, living in a home for the elderly was an important predictor of locomotor disability; marital status, whether the participant lived alone or with others, educational level, and net annual income were not independently associated with disability.

The proportion of locomotor disability in the general population attributable to a variable is determined by the association between the variable and locomotor disability, and the prevalence of the variable. Consequently a variable with a low prevalence (for example morning stiffness) will not be reflected in a high proportion of locomotor disability in the population as a whole, even if its association with locomotor disability is very strong. However, the fact that $20 \%$ of all men and $35 \%$ of all women older than 55 have joint pain somewhere in their lower limbs implies that many people in this age group suffer from loss of ability in carrying out the most basic activities needed to maintain an independent life.

The role of generalised morning stiffness is difficult to explain. This symptom originally was described as a criterion for rheumatoid arthritis, ${ }^{16}$ but showed a low sensitivity and specificity, suggesting that the reported stiffness of the limbs was not so much arthritic in origin, but had to do more with the structures surrounding the joints. We hypothesise that in those people who suffer from it, the stiffness present after arising from bed initiates locomotor disability which is prolonged and enhanced by the occurrence of joint pain. In people who do not suffer from generalised morning stiffness, joint pain at multiple sites, in particular, was independently responsible for the loss of lower limb functions.

As in all population surveys, there were sources of bias in our study. The response rate of $80.8 \%$ in men and $79.8 \%$ in women was high, and will have limited selection bias. People who refused to participate, however, were generally older (especially above the age of 80 ), and more often seriously ill or bedridden; if we therefore take into account that non-response was largely due to illness, it can be assumed that our prevalence estimates were biased towards lower levels. Incompleteness of data was caused mainly by the inability of participants to answer the HAQ questions, usually because of some cognitive impairment; this was particularly the case for the very old living in homes for the elderly. Information bias from inaccuracy of data arising because the participants misinterpreted questions may have occurred, but probably not very frequently: all data were collected during a home interview, and our interviewers were trained 
extensively and their technique standardised on a regular basis. Another source of information bias are the interviewers themselves. In spite of our efforts to ensure standardised data collection by instructing the interviewers only to explain questions, and to avoid recording their own judgments, it is possible that, especially in questions relating to disability, the assessments were influenced by the interviewers. As to questions on joint pain, the interviewers were trained to distinguish between muscle pain and joint pain: the participant was asked to point out a painful site, and the interviewer was instructed then to ask specifically if it was indeed the joint that was painful and not the surrounding muscles. However, misclassification may have occurred, especially when complaints related to the hips were presented (it is not always possible for non-medical interviewers to make the correct decision whether the hip joint is indeed the origin for the complaint).

Our prevalence estimates of disability agree with those of other Dutch studies, and international data. ${ }^{13-8}$ Previously, we assessed the prevalence of pain in the joints in the 1975-78 Epidemiologic Preventive Organisation Zoetermeer (EPOZ). Those prevalences were somewhat lower than the present findings: knee pain was present in $7.6 \%$ of men and $17 \cdot 5 \%$ of women aged 45 and over, ${ }^{17}$ compared with $12 \cdot 6 \%$ and $22 \cdot 6 \%$, respectively, in our present study of participants aged 55 years and over. Pain in the hips was reported by $6.9 \%$ of the EPOZ participants ${ }^{18}$ versus $13 \cdot 2 \%$ in our study. The origin of this difference between the studies is that the EPOZ study questioned the presence of pain at the time of investigation, not during the past month. Among more than 2000 men and women aged at least 55 years and registered at a general practice in Bristol, United Kingdom, the prevalence of knee pain was $20.1 \%$ in the men and $27.6 \%$ in the women-substantially greater than in the Dutch studies. ${ }^{9}$ Again, the difference can be explained by the way joint pain was assessed: the British study asked about pain that was present on most days for at least one month during the past year, while we asked for pain during the past month. A Finnish study assessed rheumatic complaints in the hips and knees in people aged over 50; the prevalences were in accordance with our findings: $13 \%$ for the hips and $12 \%$ for the knees in men and $11 \%$ and $22 \%$, respectively, in women. ${ }^{19}$ Our finding that the prevalence of joint pain did not increase with age also agrees with the findings of other studies. 920

Our estimates of the odds ratios for locomotor disability of joint complaints cannot be compared with most other disability studies, as they did not present measures of association. ${ }^{3-5}$ 21-24 The Bristol study reported a significantly greater frequency of disability (HAQ score $>0$ ) in subjects with knee pain than in those without at all ages $(p<0.05)$, except in men aged over $80 .^{9}$ The 1983-85 Framingham study estimated odds ratios of pain in the knees for at least one month during the past year, in 1416 people aged 60 and over, for dependence on personal help in walking of $2 \cdot 6$, and climbing stairs of $3 \cdot 7 .{ }^{8}$ In our study the odds ratios of knee pain for the same dependencies (score $=3$ on the HAQ) were both $2 \cdot 1$ in the 4530 men and women aged 60 and over.

Findings in the Rotterdam Study make clear that locomotor disability in an aging population is a problem of considerable magnitude. Although age is the major determinant, generalised morning stiffness and pain in the joints of the lower limbs are strong determinants, independent of age.

Supported by the NESTOR programme for geriatric research (Ministry of Health and Ministry of Education), the Netherlands Orgnisation for scientific research (NWO), and the Municipality of Rotterdam.

1 Odding E. Locomotor disability in the elderly. An epidemiological study of its occurrence and determinants in a general population of 55 years and over [Thesis]. in a general population of 55 years

2 Hofman A, Grobbee $D$ E, Dejong $P \quad T \quad V \quad M$, Vandenouweland F A. Determinants of disease and disability in the elderly: the Rotterdam Elderly Study. Eur f Epidemiol 1991; 7: 403-22.

3 Cunningham L S, Kelsey J L. Epidemiology of musculoskeletal impairments and associated disability. Am f Public Health 1984; 74: 574-9.

4 Lawrence R C, Everett D F, Hochberg M C. Arthritis. In: Comoni-Huntley J C, Huntley R R, Feldman J J, eds. Health status and well-being of the elderly. National Health Health status and well-being of the elderly. National Health and Nutrition Examination Survey-I epidemiologic follow-up

study. New York, Oxford: Oxford University Press, 1990.
5 Hubert H B, Bloch D A, Fries J F. Risk factors for physical disability in an aging cohort: the NHANES I Epidemiologic Followup Study. I Rheumatol 1993; 20: 480-8.

6 Pinsky J L, Branch L G, Jette A M, et al. Framingham Disability Study: relationship of disability to cardiovascular risk factors among persons free of diagnosed cardiovascular disease. Am $\mathcal{f}$ Epidemiol 1985; 122: 644-56.

7 Jette A M, Pinsky J L, Branch L G, Wolf P A, Feinleib M. The Framingham Disability Study: physical disability among community-dwelling survivors of stroke. $f$ Clin Epidemiol 1988; 41: 719-26.

8 Guccione A A, Felson D T, Anderson J J. Defining arthritis and measuring functional status in elders: methodological issues in the study of disease and physical disability. $\mathrm{Am}$ f Public Health 1990; 80: 945-9.

9 McAlindon T E, Cooper C, Kirwan J R, Dieppe P A. Knee pain and disability in the community. $B r \mathcal{F}$ Rheumatol 1992; 31: 189-92.

10 Wood P H N, ed. World Health Organisation. International Classification of Impairments, Disabilities, and Handicap. Geneva: WHO, 1980.

11 Thompson $P$ W. Functional outcome in rheumatoid arthritis. Br $\mathcal{F}$ Rheumatol 1988; 27 (suppl I): 37-43.

12 Fries J F, Spitz P, Kraines R G, Holman H R. Measurement of patient outcome in arthritis. Arthritis Rheum 1980; 23: $137-45$

13 Fries J F, Spitz P W, Young D Y. The dimensions of health outcomes: the Health Assessment Questionnaire, disability and pain scales. F Rheumatol 1982; 9: 789-93.

14 Siegert C E H, Vleming L J, Vandenbroucke J P, Cats A. Measurement of disability in Dutch rheumatoid arthritis patients. Clin Rheumatol 1984; 3: 305-9.

15 Kleinbaum D G, Kupper L L, Morgenstern H, eds. Epidemiologic research. Principles and quantitative methods. New York: Van Nostrand Reinhold, 1982; 160-4.

16 Ropes M W, Bennett G A, Cobb S, Jacox R, Jessar R A. 1958 revision of diagnostic criteria for rheumatoid arthritis. Bull Rheum Dis 1958; 9: 175-6.

17 Schouten J S A G. A twelve year follow-up study on osteoarthritis of the knee in the general population. An epidemiological study of classification criteria, risk factors and prognostic factors [Thesis]. Rotterdam, The Netherlands, 1991

18 van Saase J L C M. Osteoarthrosis in the general population. A follow-up study of osteoarthrosis of the hip [Thesis]. Rotterdam, The Netherlands, 1989.

19 Takala J, Sievers K, Klaukka T. Rheumatic symptoms in the middle-aged population in southwestern Finland. Scand f Rheumatol 1982; 47 (suppl): 15-29.

20 Bergström G, Bjelle A, Sundh V, Svanborg A. Joint disorders at ages 70,75 and 79 years-a cross-sectional comparison. Brf Rheumatol 1986; 25: 333-41.

21 Netherlands Central Bureau of Statistics. Physical disability in the population of the Netherlands 1986/1988. The Hague: in the population of the Netherlands 1986/1988.
SDU/publishers/CBS-publications, 1990.

22 Verbrugge L M, Gates D M, Ike R W. Risk factors for disability among U.S. adults with arthritis. If Clin Epidemiol 1991; 44: 167-82.

23 Yelin $\mathrm{E}$. Arthritis. The cumulative impact of a common chronic condition. Arthritis Rheum 1992; 35: 489-97.

24 Harris T, Kovar M G, Suzman R, Kleinman J C, Feldman J J. Longitudinal study of physical ability in the oldest-old. Am F Public Health 1989; 79: 698-702. 